\title{
New generation of information system for the extended enterprise
}

\author{
R. Hieber, R. Alard \\ Institute of Industrial Engineering and Management \\ at the Swiss Federal Institute of Technology (ETH) Zurich \\ Zurichbergstrasse 18, CH-8028 Zurich, Switzerland \\ Tel.: $++41-1-6320526$ \\ Fax: ++41-1-6321040 \\ e-mail:hie@bwi.bepr.ethz.ch
}

\begin{abstract}
The paper starts with a brief survey over the historical development of information systems, from simple inventory control programs over very sophisticated integrated enterprise resource planning systems (ERP) towards advanced planning and scheduling systems (APS) in the industrial environment. Thereby, the focus is not only on technical innovations, but also on the managerial impacts on industrial organizations. Based on these insights, this new generation of standard software packages, also known under the expression Supply Chain Management (SCM) solutions, will be discussed. The purpose of this study is to analyze and compare current SCM-solutions versus existing information systems which are operating in different industry branches. Based on the experience of our own research and the insight of our industry partners, strengths and weaknesses of these new systems will be revealed. The findings of these study will end up with a potential gap between the technological capabilities of theses systems and the organizational needs.
\end{abstract}

\section{Keywords}

Logistics, Enterprise Resource Planning, Supply Chain Management, Advanced Planning and Scheduling

\section{INTRODUCTION}

Today's industry without any information technology (IT) support is unthinkable. The market of standard information systems has been one of the fastest growing markets. Increase of sales of software solution providers over $60 \%$ was not seldom 
$\left(\mathrm{SAP}^{1}\right)$. The development in the newest market segment, the Supply Chain Management software is even more amazing. An international market research study reveals that this market is still growing enormously, e.g. Benchmark Partners (Benchmark Partners, 1998) anticipates a growth rate from $\$ 350$ mio. in 1996 up to $\$ 1,600$ mio. in 1999 and expected $\$ 4,000$ mio. in 2001. What are the reasons for this tremendous growing and the significant importance in today's business arena? First, this paper will give some reasons for this development and the possible managerial impacts on industry.

\section{INNOVATION DRIVERS IN INDUSTRY}

Two substantial shifts in the industrial environment have major impact on the development of present information systems.

\subsection{Globalization of Industry}

Companies are more and more integrated in logistics and production networks and hence, the efficiency of their business is heavily dependent on the external relations to their business partners. As a consequence, concepts like supply chain management, virtual organizations or the extended enterprise are gaining more and more importance. For example, in the semiconductor industry, the globalization is quite common. Wafer raw material supplier in Europe, manufacturing of WaferFabs in Asia and final system assembly in the United States (Sturm, 1998). Therefore, companies who can most effectively gather vital information along the whole supply chain and quickly act upon it, are gaining competitive advantages.

\subsection{Information and Communication Technology}

The technical innovations have developed in a breathtaking pace. First of all, the declining price of hardware components has just made the new very memory and CPU intensive software solutions possible. Then, the idea of linking together information systems has been developed. Global Client Server architecture and the World Wide Web (WWW) are the results of this development. Companies recognize that tight interaction with their suppliers and customers can deliver valuable information for acting in advance on market changes.

\section{DEVELOPMENT OF INFORMATION SYSTEMS}

At the very beginning in the sixties, none of us has even thought about the overwhelming development of industrial standard information system, like enterprise software packages from SAP or Oracle Corporation. The first software solutions for industry were mainly simple inventory control applications

${ }^{1}$ SAP Business Report 1997 
(Wortmann, 1998). Later on, the concept was extended to Material Requirement Planning (MRP) software solutions. The first step towards using software as a planning tool has begun. Industry recognized the tremendous benefits and extended further the MRP concept to Manufacturing Resource Planning (MRPII) concept. Now, capacity planning and Master Production Scheduling (MPS) were included and made an integrated view in the production possible. Hereby, the focus has still been in the manufacturing area. In the nineties, the boom of standard enterprise software packages has been started. By adding additional functions like finance, human resources, sales and marketing or distribution, the now so called Enterprise Resource Planning (ERP) software appeared on the market.

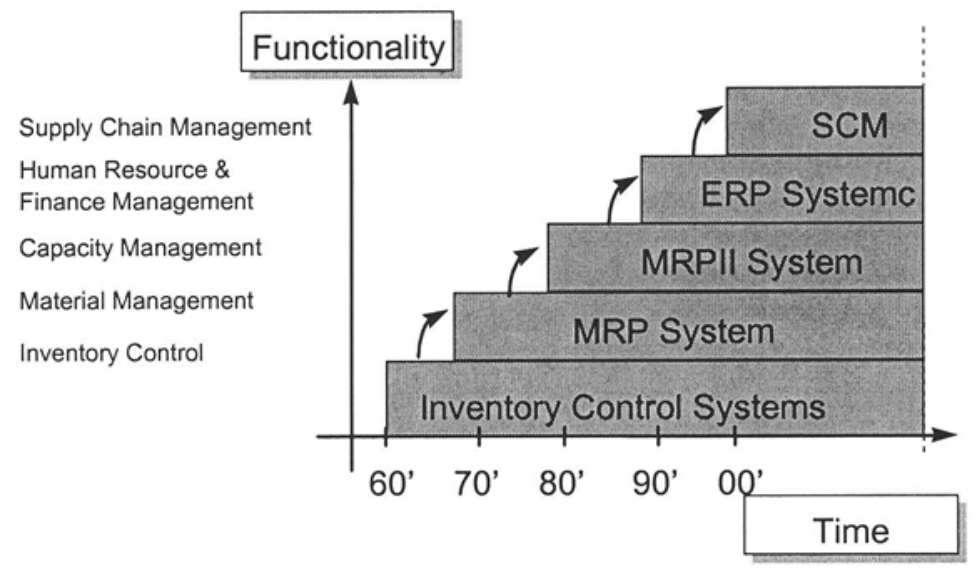

Figure 1 Development of Information Systems

ERP systems are standard application programs, which support execution of almost every business process. They promise the seamless integration of all the information flowing through a company - financial and accounting information, human resource information and customer information (Davenport, 1998). Astonishing fact is, regardless of the branch the industry is into, this standard software can be used.

Today, ERP-Systems take up the biggest part of industrial information systems. Additional to them, optimizing tools for special applications and analysis tools mainly for simulation are concurrently on the market (Hicks, 1997). The latest generation of information systems in industry are the Supply Chain Management solutions, which will have major influence on the three other segments. 


\section{Current Solutions of Information Systems}

\begin{tabular}{|c|c|c|c|}
\hline ERP-Systeme & $\begin{array}{l}\text { Supply Chain } \\
\text { Management } \\
\text { Tools }\end{array}$ & $\begin{array}{l}\text { Optimizing } \\
\text { Tools }\end{array}$ & $\begin{array}{l}\text { Analysis } \\
\text { Tools }\end{array}$ \\
\hline $\begin{array}{l}\text { O Push-Principle } \\
\text { O Management of } \\
\text { almost every business } \\
\text { Process, like } \\
\text { production planning, } \\
\text { finance, etc. } \\
\text { O Transaction System } \\
\text { Revealing the current } \\
\text { state of a company } \\
\text { Data Management } \\
\text { Dast-based } \\
\text { P }\end{array}$ & $\begin{array}{l}\oplus \text { Revealing the } \\
\text { complete supply chain } \\
\odot \text { Enhance transaction } \\
\text { systems } \\
\odot \text { based on } \\
\text { ERP-Data base } \\
\text { "planning and } \\
\text { decision tool" } \\
\end{array}$ & 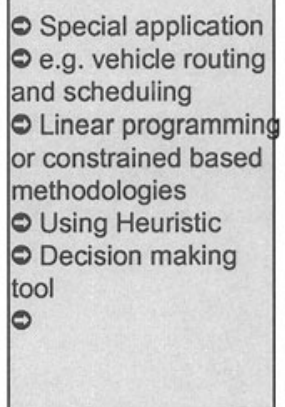 & $\begin{array}{l}\text { Simulation tools } \\
\text { Modelling of } \\
\text { dynamic processes }\end{array}$ \\
\hline $\begin{array}{l}\text { Main representative } \\
\text { SAP, Baan } \\
\end{array}$ & $\begin{array}{l}\text { Main representative } \\
\text { i2, Manugistics }\end{array}$ & $\begin{array}{l}\text { Main representative } \\
\mathrm{i} 2 \text {, llog }\end{array}$ & $\begin{array}{l}\text { Main representative } \\
\text { Simple ++ }\end{array}$ \\
\hline
\end{tabular}

Figure 2 Classification of current Information Systems (Hicks, 1997)

\section{SUPPLY CHAIN MANAGEMENT TOOLS}

The existing solutions of ERP software packages are mainly centralized, companyspecific customized, inheterogene in the own organization and inflexible to adapt to new conditions. Only a few solutions do support process oriented structures in the own organizations, however, not to mention of external organizational processes. As a consequence, these system have been further developed in means of functionality and strategic and operational use. Especially by using Internet enabled technologies and the World Wide Web, SCM-tools make an integration of different systems possible and extend the functionality of existing ERP-solutions over their own organizational boundaries. Therefore, the systems "should" deliver integration in the following five crucial activities of every business (compare figure 3):

- Configuration - the ability to model and configure the supply chain to link different partners for an optimal customer solution,

- Planning - the ability to anticipate the future and the respond to changing situations by providing an integral "end-to-end" view,

- Optimization - the ability to find the best solution for the WHOLE supply chain,

- Execution - the ability to standardize and automate the daily business within the supply chain,

- Control - the ability to identify the weak chain and locate the possible impacts on the common business. 


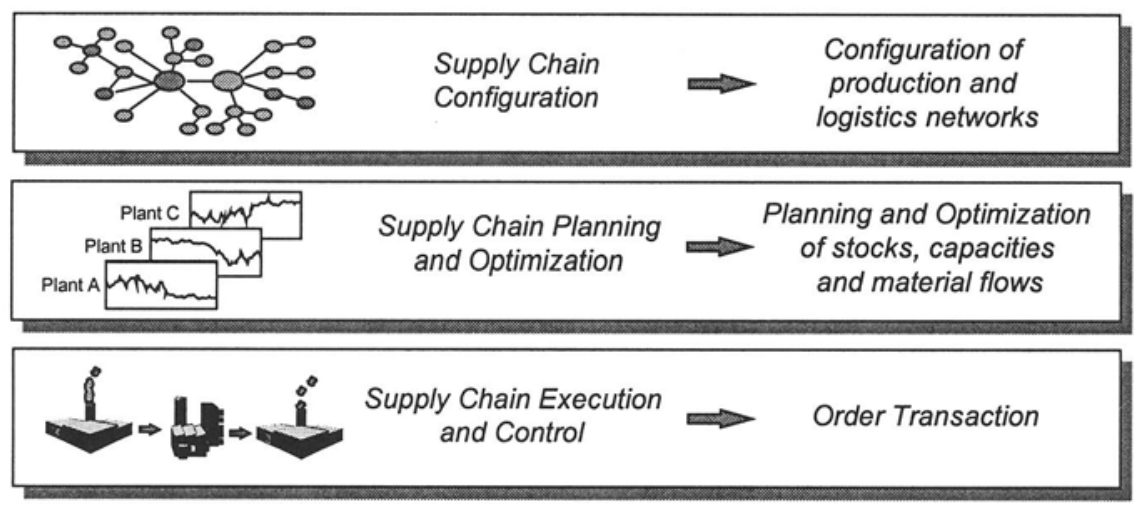

Figure 3 Crucial activities for SCM-Tools

Some examples of the functionality of SCM-tools, which claim to fulfill these five crucial activities, will be briefly described in the following paragraph.

\subsection{Functionality of current Supply Chain Management Tools}

Current SCM-Tools claim to extend the functionality of existing ERP-solutions over the own organizational boundaries and allow companies to extend planning visibility into their supply chain and distribution chain in order to make better decisions regarding, for example, when to buy production goods, manufacture product, and initiate distribution. The focus of the current solutions is still mainly the planning side rather the execution side (compare figure 4). Demand, Procurement, Distribution, MPS and Transportation Planning are the main modules in the planning area. In the execution area, available-to-promise (ATP) or, in general, real-time customer service, vendor managed inventory (VMI), and customer product configuration are the offered functionality, there.

New, comparing to ERP-solutions, are the modules to model and configure the network in which a company is integrated. The Supply Chain Network Designer allows to demonstrate graphically the flow of materials and the interdependencies between customers and suppliers. Additionally, cross-network functionalities, like supply chain messaging (alerts), performance management (network performance measures) and monitoring (exchange) of information, complete SCM tools. Hence, SCM-Tools do not replace the infrastructure of ERP-systems. SCM-tools work together with ERP packages and rely on many of its functionalities and transactions. 


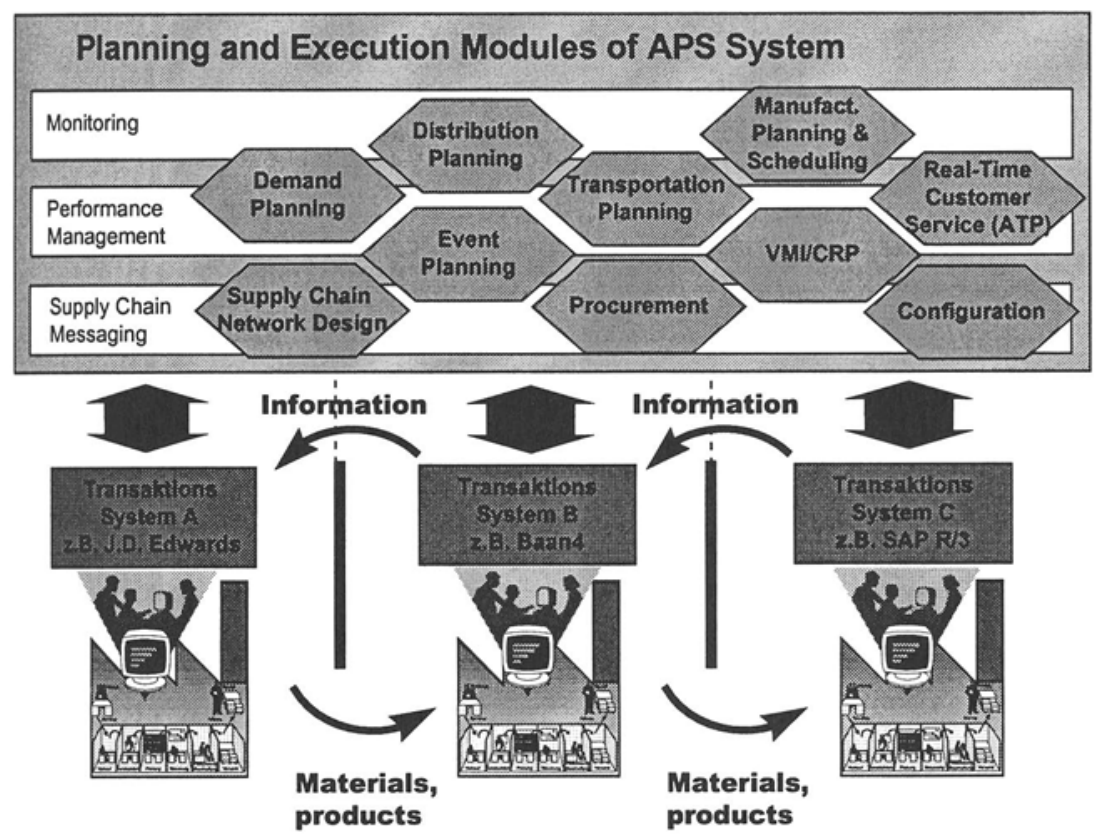

Figure 4 Main modules of SCM-Tools

\section{CONCLUSIONS}

As first experience have shown, Supply Chain Management software offers a new additional functionality for industry. This information technology package promises to close the gap between the different ERP-systems of companies and ensure an integrated view of a supply chain. But there are still several concerns related to these systems. As the reference lists of software vendors show, only large enterprises are users of these systems. Therefore, not only the price is a reason for. While systems that synchronize supplier operations and distribution networks are invaluable to a company such as Nestle or Pepsi-Cola, which have significant power and influence over their suppliers and distributors and can execute on the plan arrived at through an SCM-tool, we must remember that the vast majority of companies are in another company's supply or distribution chain. These companies take their orders from a powerful customer or set of customers, and do not have the organizational power to bend supplier or distributors to their will. As a consequence, since they do not have the same influence over processes outside their company, they are more focused on synchronizing production within their own four walls. However, the approach to reach a global optimum in a network must be reached collaboratively. Therefore, the structure and usage of the SCM systems must be designed this way, that every partner of a supply chain can participate in the whole business. As a consequence, a shift in corporate culture is 
necessary towards a co-operation based on a win-win partnership and, most important, trust.

\section{REFERENCES}

Benchmark Partners (1998) Supply Chain Planning \& Scheduling. Supply Chain Market Review, Cambridge.

Davenport, T.H (1998) Putting the Enterprise into the Enterprise System. In: Harvard Business Review, July 1998, p.:121-131.

Hicks, D.A. (1997) The Managers Guide to Supply Chain and Logistics ProblemSolving tools and Techniques, Part II: Tools, Companies and Industies. IIE Solutions 29 (1997) 10, pp. 1-18.

Sturm, J. (1998) Global Production-Network in the Semiconductor Industry. In: Proceedings 3. Stuttgarter PPS-Seminar, 18. Juni 1998; Stuttgart, Germany, pp.109-121, Fraunhofer IRB.

Wortmann, J.C. (1998) Evolution of ERP-Systems. In: Bititci, U. \& Carrie A. (Ed.): Strategic Management of the Manufacturing Value-Chain. Proceedings IFIP Conference, 26.-28. August, 1998, Troon, Scotland, UK, pp.11-23. Kluwer Academic Publishers.

\section{BIOGRAPHY}

Ralf Hieber: Born in 1971, Studies in Mechanical Engineering with the major in Manufacturing Systems at the University of Stuttgart (GER), Graduation (Dipl.Ing.) in 1997, complementary studies of Industrial Engineering as a scholar at the University of Wisconsin-Madison (USA), 1996 graduation (M.Sc.) in Manufacturing Systems Engineering. Since 1997, scientific assistant of Prof. Dr. P. Schönsleben at the BWI of ETH Zurich with the research areas: Organization and Management of Production Network Structures and Virtual Enterprise.

Robert Alard: Born in 1972, Studies in Mechanical Engineering at the Aachen University of Technology (RWTH Aachen) with the main subjects in Organization, Planning, and Cybernetics. He continued studies as a scholar of Erasmus at the Swiss Federal Institute of Technology Zurich. Graduation (Dipl.Ing.) in 1997 at the Aachen University of Technology. Since 1998, he is working as a research assistant of Prof. Dr. P. Schönsleben at the BWI - Swiss Federal Institute of Technology Zurich. Research areas: Supply chain management, organization of network structures, virtual enterprises, and their supply through new information and communication tools. 